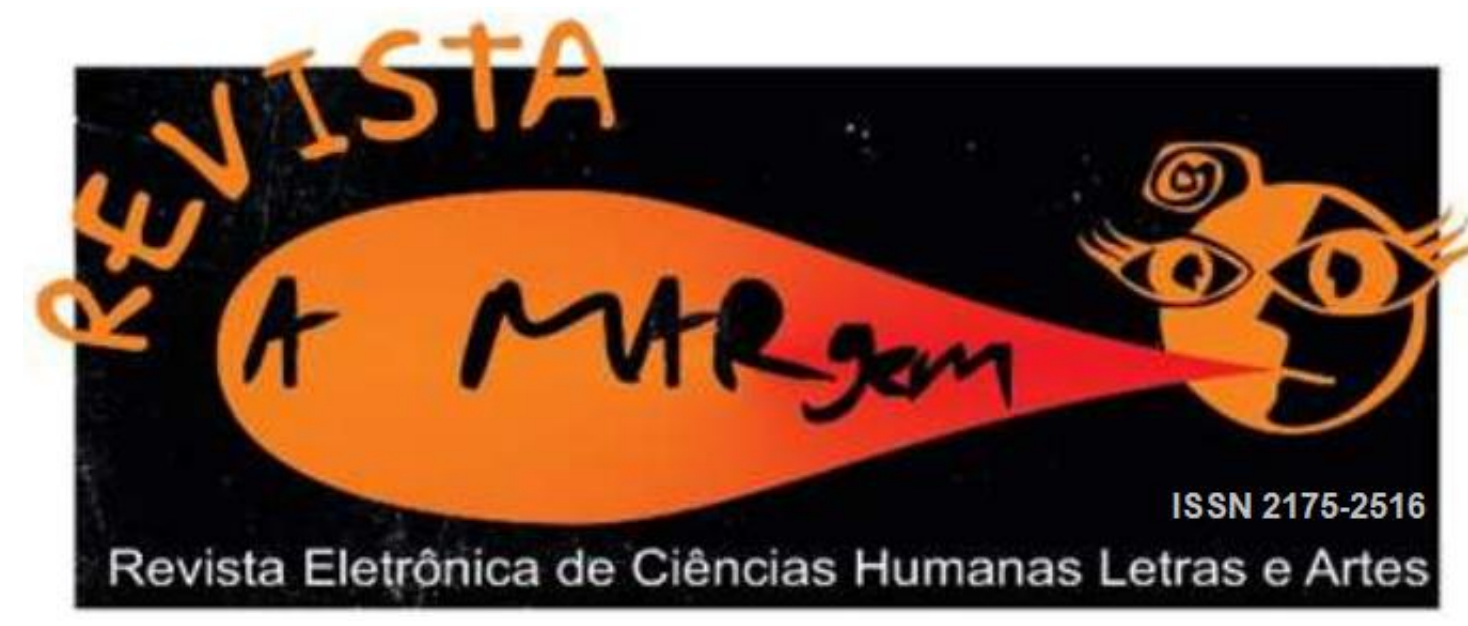

\title{
RESENHA DO LIVRO "REVISÕES DO CÂNONE: ESTUDOS LITERÁRIOS E TEORIAS CONTRA-HEGEMÔNICAS"
}

\section{Gabriel Marinho Camargo Universidade Federal de Minas Gerais - UFMG}

Book review: "Revisões do Cânone: estudos literários e teorias contra-hegemônicas"

MITIDIERI, André Luis, CAMARGO, Fábio Figueiredo, SACRAMENTO, Sandra Maria Pereira (Orgs.). Revisões do Cânone: estudos literários e teorias contra-hegemônicas. Uberlândia: O sexo da palavra, 2020. 404p.

Revisões do Cânone: estudos literários e teorias contra-hegemônicas parte de duas necessidades que se interpolam: uma sociopolítica e uma metodológica, ou ao menos atende a ambas - evito assim uma leitura unidirecional de cada capítulo separadamente, principalmente os que apresentam leituras mais singulares. O conjunto de textos presentes no livro pretende, em sua organização, apresentar meios para uma desconstrução do cânone literário e uma pluralização dos métodos de leitura, respondendo à marginalização de sujeitos e textos por normas hegemônicas.

Assunto corrente nos Estudos Literários nos últimos quarenta anos, aproximadamente, a desconstrução do cânone é um projeto que se edifica desde os pontos de convergência entre autores estruturalistas - em relação ao questionamento da arbitrariedade das instituições - e toma mais forma na culminância do desconstrucionismo em Jacques Derrida. Porém, são os desdobramentos dessa corrente nos estudos de gênero - principalmente em Judith Butler - que representam a face mais influente, para o aqui analisado Revisões do Cânone, desse longo processo que desencadeou a "crise do método", como aponta Marcus Freitas (2018). 
A partir desse longo movimento, que não deve ser visto como uniforme em momento algum, o qual pretendia apagar barreiras responsáveis por separar obras "atemporais" ou "universais" das "outras", há uma cisão no mundo acadêmico.

Há aqueles que, como o crítico literário Harold Bloom, entendem que uma desconstrução do cânone resulta num rebaixamento dos textos cultuados por séculos ao nível daqueles "outros", indignos. Bloom reage aos Estudos Culturais - que os nomeia parte da "escola do ressentimento", composta em grande parte pelos estudos que formam esse movimento do pensamento ao longo do século XX aqui esboçado de forma muito rudimentar promovendo, em seu $O$ cânone ocidental um estudo dos 26 autores que considera os pilares da literatura ocidental. Contudo, embora realize uma leitura atenciosa e profunda desses autores especialmente de Shakespeare, considerado o centro de seu cânone - o estudo acaba por restringir ainda mais o sistema que já era exclusivo, transformando o cânone numa propriedade quase particular de Bloom.

O outro lado, que, seguindo pelos caminhos abertos por Derrida (1999) e Butler (1993), busca uma aproximação da literatura com a realidade - com critérios pautados em perspectivas plurais, diferentemente da sociologia da literatura do século XIX, pioneira no projeto de aproximação de ambos os campos -, transformando uma perspectiva filosófica inicialmente anti-humanista (Derrida) numa humanista sem precedentes. Dado que o anti-humanismo de Derrida se constituía pela consideração do humanismo como uma limitação da potência da linguagem, é surpreendente ver trabalhos que se alimentaram da obra do filósofo conseguirem aplicar o desconstrucionismo sem fugir dos objetivos de inclusão e acolhimento das minorias pauta eminentemente humanista. As questões sobre a existência das autoridades do texto, especialmente aquela sobre a figura do autor levantada por Roland Barthes (1984) e Michel Foucault (2011), passam a ser tratadas como pressupostos capazes de desconstruir as barreiras entre texto e realidade. Sendo assim, torna-se possível o estudo das "outras" obras, como aquelas que transitam entre o ficcional e o real sem se preocupar com as amarras de cada campo - no caso da autoficção -, assim como muitas outras ignoradas pela heteronorma.

Revisões do Cânone, portanto, adentra esse debate na oposição máxima a tudo representado por Bloom. A busca pela desconstrução dos binarismos, por séculos responsáveis por impossibilitar a inclusão daqueles que lutam diariamente por espaço na sociedade, se mostra aqui em profundidade. Logo no primeiro texto somos apresentados a todo o paradigma dos estudos literários perpetuado desde Aristóteles até meados do século $\mathrm{XX}$, para então o confrontarmos com uma proposta metodológica que centraliza a interpretação, numa espécie 
de enfrentamento da crise do método. Todavia, tal interpretação deve ser munida de um aparato crítico mais sólido que o da estética da recepção, uma das causadoras da crise, como bem aponta Regina Zilberman (2020), que assina o capítulo "Mimese, representação, interpretação".

A obra é dividida em três seções: a primeira, "representação e visadas contemporâneas", dá o pontapé inicial para entendermos o atual estado dos Estudos Literários. om textos voltados para uma contextualização geral da teoria da literatura no século XXI, somos apresentados a uma série de problemas e possíveis caminhos dentro do campo.

A próxima seção, "mulher e literatura", responsável por reunir textos que abordem produções femininas no mundo literário e acadêmico, adentra o espaço aberto pela primeira seção com um foco especial na figura da mulher e na problemática da identidade, herdada pela quarta onda do feminismo.

Por fim, a seção "diversidade / ou dissidências sexuais e de gênero", posiciona os estudos focados na dissidência sexual e suas representações na literatura. Sendo assim necessário dizer que todos os textos presentes no livro se cruzam, seja pelo arcabouço teórico convergente, ou nas aplicações em textos literários. Portanto, aqui se intercalam textos que buscam uma melhor compreensão do material teórico que constitui as propostas metodológicas de enfrentamento à crise com estudos que, embora contemplem criticamente o material teórico, se aventuram mais na aplicação de tais metodologias em análises literárias, evidentemente, com o devido foco proposto por cada seção.

Nesse amálgama, encontramos análises determinadas a desconstruir o cânone de fato; aplicações do juízo crítico mais refinado para superar ideais universalistas. Destaco as abordagens sobre a autoficção - tema que desponta em alguns momentos da obra, funcionando como uma espécie de materialização de todo o aparato teórico discutido -, em particular o texto “Autoria e (meta)autoficção no século XXI”, no qual Telma Borges propõe uma outra leitura do que se conhece por autoficção, trazendo à luz o texto Insubmissas lágrimas de mulheres, de Conceição Evaristo. Essas análises de textos autoficionais, que acabam por se realizar como textos do gênero - especialmente o último trabalho, de Paulo César García - representam toda a complexa colaboração que há, entre os estudiosos que assinam o livro, para aproximar literatura e vivências.

Quando disse acima que a obra atende a ambas as necessidades (sociopolítica e metodológica), tenho em mente que a proposta é humanizar todo o processo que envolve desde a produção de textos literários quanto de sua recepção, seja dentro ou fora do mundo acadêmico. Entretanto, dizer que elas atendem a essas necessidades, e não necessariamente partem delas, 
preserva os objetivos de cada texto em especial de confrontar outros problemas relativos ao campo que estudam, como é o caso da autoficção.

Consoante, por se tratar de uma reunião de textos escritos por acadêmicos extremamente qualificados, nos vemos diante de propostas que criticam as próprias perspectivas que galvanizam os processos de desconstrução do cânone. Visões críticas sobre as ondas do feminismo; a problematização da tradução dos estudos queer; a desestabilização do conceito de identidade; todas essas realizações presentes no livro acabam por confirmar a necessidade da constante revisão. Desmantelar teses engessadas, que perpetuem binarismos; universalismos; códigos morais hegemônicos e até mesmo metodologias críticas de autores muito reconhecidos no universo literário e acadêmico, se mantém como o objetivo central na obra. É por meio da democratização e da busca constante por conhecimento que se construirá uma sociedade mais digna. $\mathrm{O}$ reconhecimento da situação excludente em que vivemos é o primeiro passo de um longo caminho que devemos trilhar caso queiramos viver em um mundo que proporcione amparo para os que sofrem com tal violência. Embora a obra aponte isso frequentemente, ela, reunindo autores de diversas regiões do país, parece se abster de uma previsão otimista ou pessimista do futuro a curto prazo para o Brasil - resultado que por si só já é otimista de algum modo, uma vez que não ser pessimista quanto a esse futuro a curto prazo é quase inevitável devido às condições políticas atuais.

Sinto que é necessário ressaltar, que a obra, assim como os Estudos Culturais, não pretende descartar nem mesmo substituir a leitura dos textos de Camões, Cervantes, Dante, Homero, Kafka, etc., mas sim estabelecer um espaço que permita estudos que não levem em conta critérios qualitativos particulares que se passem por universais. Infelizmente, grande parte do lado conservador da academia, apegada ao formalismo e a todas as pautas excludentes mascaradas de "universalistas", é oposta à ideia de desconstrução do cânone por enxergar nela um perigo para a "Grande Literatura". Evidentemente, isso parte de perspectivas elitistas avessas ao descarte dos moldes engessados que compõem suas perspectivas metodológicas. Porém, esse embate está longe de terminar.

Não é necessário aderir às perspectivas propostas por cada texto para ser antihegemônico, como a reunião destes trabalhos bem evidencia, mas sim se preocupar com os pontos cegos de nosso conhecimento. A crítica literária deve sempre "colocar em crise" - e não se considerar completa diante daquilo que analisa. Ela deve estar em constante devir, assim como nós, e contemplar o que há de mais especial em cada obra e cada autor sem cair em modismos ou na simples apologia. Caso queiramos compreender de fato o que há na literatura 
que diga respeito ao mundo em que vivemos, ou que responda a ele de alguma maneira, não podemos confiar em valores exclusivos ou seleções essencialistas. Devemos reconhecer nossa ignorância perante a vastidão de textos que foi apagada ou ignorada pela história e não nos deixarmos abater por isso. É por meio do reconhecimento de nossa insuficiência que procuramos o outro - e nele encontramos meios para contorná-la, mesmo que parcialmente.

\section{Referências}

BARTHES, Roland. O Rumor da língua. Trad. Mário Laranjeira. São Paulo: Martins Fontes, 2005.

BLOOM, Harold. O cânone ocidental: os livros e a escola do tempo. Trad. Marcos Santarrita. Rio de Janeiro: Objetiva, 1994.

BUTLER, Judith. Bodies that Matter. New York: Routledge, 1993.

DERRIDA, Jacques. Gramatologia. Trad. M. Schnaiderman e R. J Ribeiro. São Paulo: Perspectiva, 1999.

FOUCAULT, Michel. Ditos e escritos III: Estética: literatura e pintura, música e cinema. Trad. Inês Autran Dourado. Rio de Janeiro: Forense, 2011.

FREITAS, Marcus Vinicius de. O Problema do método nos Estudos Literários. 2018. (Apresentação de Trabalho/Conferência ou palestra).

ZILBERMAN, Regina. Mimese, representação, interpretação. In: MITIDIERI, André Luis, CAMARGO, Fábio Figueiredo, SACRAMENTO, Sandra Maria Pereira (Orgs.). Revisões do Cânone: estudos literários e teorias contra-hegemônicas. Uberlândia: O sexo da palavra, 2020. 